The Research Journal of the Costume Culture

[Original Article]

Received May 17, 2017

Revised June 09, 2017

Accepted June 12, 2017

${ }^{\dagger}$ Corresponding author

(sjy73716@jj.ac.kr)

ORCID

Joonyoung Shim

http://orcid.org/0000-0001-9129-7820
pISSN 1226-0401

RJCC Vol.25, No.3, pp.405-418, June 2017

https://doi.org/10.7741/rjcc. 2017.25.3.405

\section{A study on the rental Hanbok \\ - Focusing on the market and consumer changes between 2006 and 2016 -}

\author{
Joonyoung Shim ${ }^{\dagger}$ \\ Dept. of Home Economics Education, Jeonju University, Korea \\ 대여 한복에 대한 연구 \\ - 2006년과 2016년 시장과 소비자 변화를 중심으로 - \\ 심 준 영 $^{+}$ \\ 전주대학교 가정교육과
}

\begin{abstract}
The purpose of this study is to investigate changes in the rental Hanbok market and consumer during the past 10 years. This study was done by analyzing internet news about rental Hanbok and in-depth interview. The results provide basic data that can be used to understand the rental Hanbok market. Results showed the followings: First, the rental Hanbok market has expanded and consists of two types of rental Hanbok; ceremonial and experiential. The experiential Hanbok is new but a big part in rental Hanbok market. It is not existed until 2007 but it accounted for more than $60 \%$ of internet news about rental Hanbok in 2016. Second, there is a significant difference in consumer behavior between the two types of rental Hanbok. Ceremonial Hanbok showed consistent consumer behavior between 2006 and 2016. Consumer want to get benefits such as TPO(occasion suitability), economy, exhibition, trendy and exceptionality through renting Hanbok. On the other hand, experiential Hanbok, consumers are motivated by having unique, conformity and sharing memories. Based on these results, different sets of information reveal the unique features of the two types of rental Hanbok. And also needed to develop new designs and marketing strategies for them.

Keywords: rental Hanbok(대여 한복), internet news(인터넷 뉴스), ceremonial Hanbok(의례용 한복), experiential Hanbok(체험용 한복)
\end{abstract}

\section{Introduction}

최근 인터넷에서는 한복을 입고 노는 젊은이들의 사진을 흔히 볼 수 있다. 이미 지를 중심으로 소통하는 소셜네트워크서비스(SNS)에서 한복을 키워드로 검색하면 수십만 건의 게시물이 검색된다. 해외 배낭여행을 가는 대학생이 한복을 챙겨간다 거나, 우정사진 또는 커플사진을 찍는데 한복을 입는 것이 유행이라고 할 정도로 많은 젊은이들이 한복입기를 즐기고 있다. 
젊은이들의 한복 착용에 대해 연구한 Yoon(2012) 은 차세대의 한복 소통에 관한 연구에서 10 대와 20 대 젊은이들이 한복에 대해 만화, 음악 그리고 놀이를 통해 소통하고 있다고 밝혔다. 특히 놀이를 통한 소 통 부분에서 ‘한복 놀이단'과 ‘한복입기 좋은 날’이라 는 단체의 활동을 주목했는데, 이들은 각종 행사에 한복을 입고 참석하여 대한민국을 알리고, 소모임에 서도 한복을 착용하고 즐기는 모습을 보여준다. 이러 한 단체 활동 외에 개인적 한복 착용도 관찰되는데, 한복을 입고 인사동이나 한옥마을 등에서 사진을 찍 으며 노는 10 대들을 '한놀족'이라고 지칭하는 신조어 가 등장할 정도이다(Han, 2016).

그러나 젊은이들의 한복입기 열풍에도 불구하고, 한복 업계의 상황은 밝지 않다. 통계청에 따르면, 2007 년 4,562개였던 한복 제작업체가 2014년에는 3,054개 로 급감하였고, 소매업체의 매출액도 2009년 984억 원에서 2014년 863억 원으로 줄어들어, 전체적으로 한복 업계가 축소되고 있다고 밝혔다(Kang \& Kim, 2016). 한복 소비 시장과 한복 업계 사이에서 나타나는 이러한 차이는 한복 소비 방식의 변화에서 그 원인을 찾을 수 있을 것이다. 젊은이들의 한복 열풍에 대한 기사를 살펴보면, 대여점에는 봄바람이, 맞춤시장에 는 찬바람이 불고 있다고 표현하고 있는데, 이를 통 해 한복 소비가 주로 대여 형태로 이루어진다는 것을 알 수 있다(Kim, 2016).

대여를 통한 한복 소비가 새롭게 나타난 현상은 아 니다. 그 동안 한복은 구매 가격이 비싸지만, 착용 빈 도가 거의 없는 의례용 복식으로 용도가 변하면서 대 여 서비스를 이용하는 것이 합리적 소비라고 소개된 바 있다. 실제 의류 대여 시장에서 대표적 대여 품목 으로 여겨지는 한복은 결혼식이나 부모님 생신잔치 또는 자녀의 돌잔치 등과 같은 가족 행사에서 필요에 따라 대여하는 경우가 많았다(Shim, 2007). 그런데 이처럼 필요에 의해 한복을 대여하여 소비하던 기존 의 소비와는 다른 한복 대여 소비가 젊은이들에 의해 일종의 놀이문화로 나타나고 있다. 가족 행사를 위해 선택한 한복과 놀이나 체험 등을 위해 선택한 한복은 스타일이나 추구혜택 및 평가 요소 등 여러 부분에서 차이를 보이고 있지만, 한복 대여 소비에 대한 관련 연구는 거의 없는 상황이다.

따라서 필요에 의해 선택한 한복과 즐기기 위해 선
택한 한복을 모두 포함하는 전체 대여 한복에 대한 연 구가 다각도로 필요하다고 생각된다. 이에 본 연구에 서는 가장 먼저 대여 한복 시장의 변화를 확인해 보고 자 한다. 이를 위해 2006년과 2016년에 대여 한복에 관해 작성된 인터넷 뉴스 분석을 통해 업계의 변화를 살피고, 시장에 존재하는 대여 한복의 유형에 대해 확 인하고자 하다. 또한 대여 한복 이용 경험이 있는 소비 자들을 대상으로 심층면접을 실시하여 대여 한복에 대한 소비자들의 요구를 확인하여 대여 한복 산업에 대한 이해를 돕는 기본적인 자료를 제공하고자 한다.

\section{Background}

\section{Hanbok}

우리나라 전통 복식인 한복은 시대 변화에 따라 형 태와 용도가 변해왔고, 이와 함께 다양한 명칭도 등 장하였다. 한복 브랜드의 현황과 미적 특성에 대한 연 구에서 Bae, Lee, and Kim(2016)은 1881년부터 2015 년까지 나타난 한복을 형태에 따라 한복, 개량한복, 민족한복, 생활한복, 신한복으로 구분하였다. 그리고 인터넷 커뮤니티를 통한 전통한복의 정보탐색 및 구 매의식에 관한 연구에서 $\operatorname{Kim}(2012)$ 은 전통한복, 생 활한복, 퓨전한복의 세 가지 용어를 사용하였다. 한복 을 지칭하는 명칭은 다양하지만, 실생활에 착용 가능 하도록 변화된 한복과 전통을 유지하는 한복의 두 가 지 형태로 나누어 볼 수 있다.

먼저 실생활에 착용 가능하도록 변화된 한복은 1980 년대까지의 '개량한복', 1985 년 이후에 등장한 '생활 한복' 그리고 2014년 이후 한복진흥센터에서 실시한 '신한복 개발 프로젝트'를 통해 발표된 '신한복' 등이 대표적이다(Hanbok Advancement Center, n.d.). 각각 의 특성을 살펴보면, 첫째, 개량한복은 전통한복의 불 편함을 개선하기 위해 기능성과 활동성을 고려하여 개발한 통치마와 저고리를 의미하고, 둘째 생활한복 은 전통한복의 형식과 이미지에 현대적 심미성을 조 화시킨 것으로, 전통한복에 기능적인 요소를 가미한 것으로 볼 수 있다. 마지막으로 신한복은 기존 한복 의 불편함을 개선하고, 일상 속에서도 편하게 입을 수 있는 대중적인 한복을 뜻한다(Bae et al., 2016). 개 량한복, 생활한복, 신한복 등 변화된 한복은 공통적으 로 '한복'의 불편함을 개선하여 실생활에 착용 가능 
하도록 만드는 것을 목표로 하고 있다. 이를 위해 유 치원 어린이를 위한 교복이나 중, 고등학생 교복 그리 고 고령 남성을 위한 디자인 개발과 생활한복용 소재 개발 등(Chung \& Lee, 2003; Hong, 2009; Kim, Cho, \& Chung, 1999; Kim, 2005; Kim, 2017; Lee, 2009; Park, H.-S., 2005; Son, 2006; Yoon, 2009) 다양한 연 구가 진행되고 있다.

전통을 유지하는 한복, 즉 전통한복은 앞서 살펴본 변화된 한복과는 달리, 조선시대부터 착용해왔던 우 리 민족의 한복 중 전통미를 고수하고, 옛것을 지키 고자 하는 의지가 강하게 나타나는 한복이라고 할 수 있다(Bae et al., 2016). 현대적 활용을 위해 전통한복 의 미적 특성을 연구한 $\operatorname{Kim}(2010)$ 에 따르면, 전통한 복은 전통미, 격식미, 상징미, 자연미 등의 네 가지 미 적 특성을 가지고 있다. 전통미란 한복의 기본적 구 조나 색채, 소재 등의 구성요소에 전통복식의 형태, 색채, 소재를 표현하는 것(Geum, 1988)이고, 격식미는 큰 부피감을 지닌 의례복에서 주로 나타나는 형식에 비중을 두는 장중하고 엄숙한 느낌(Geum, 1990)을 뜻한다. 상징미란 한국인만의 독특한 성정과 생활양 식에서 우러난 자연스러운 해학미(Kim, 2010)이고, 자연미는 풍성하고 여유로운 형태감과 비규칙적인 비 례감 또는 여백의 미(Geum, 1988)가 전통한복을 통해 나타나는 것을 말한다. 이러한 특성을 종합해 보면, 전통한복은 전통 소재와 색채를 사용하고, 큰 부피감 을 지닌 풍성하고 여유로우며, 한복의 기본 구조를 충실하게 따르는 한복을 뜻한다. 그리고 이러한 특성 들은 한복이 일상생활에서 착용하기 어려운 옷이라 는 이미지를 갖게 하고, 특별한 행사에 의례적으로 착용하는 예복의 성격을 강하게 했다고 볼 수 있다.

현재 시장에서 한복이라는 단어는 뚜렷한 구분이 없이 사용되고 있지만, 본 연구의 대상은 특별한 행사 에서 착용되거나 놀이로써 일시적으로 착용하는 경 우에 선택되는 전통 한복으로 한정하여 일상생활에 서 착용하는 변화된 한복과 구분하고자 한다.

\section{Rental Hanbok}

대여는 사전적으로 돈을 받고 자기의 물건을 남에 게 빌려준다는 것을 의미한다. 우리나라의 대여업은 1986년 한국개발리스가 대여업을 허가받으면서부터 본격화되었다. 사단법인 한국렌탈협회에 따르면 기업
시장을 중심으로 시작된 대여업은 2006년부터 개인 시장이 확대되면서, 2016년 기준 2 만 개가 넘는 기업이 사업을 영위하는 10 조 원 이상의 규모를 가진 시장으 로 성장하였다(Korea Rental Association, n.d.). 대여 업체에서 주로 대여되는 의복은 가격이 비싸거나, 꼭 필요하지만 일상적으로 활용이 힘든 경우 또는 착용 빈도가 적은 의복 등이 포함되며, 무대복이나 한복 등이 포함된다.

한복은 의생활의 변화 속에서 실생활에서 착용 가능 하도록 변화한 한복과 전통한복으로 나누어졌다. 그런 데 전통한복의 경우, 결혼식에 신부가 착용하는 한복 과 혼주의 한복이 다르고, 결혼식에 참석하는 하객의 한복도 다르다. 신부의 경우, 녹의홍상 계열을 많이 입 는데, 아이를 낳은 후 돌잔치에서는 그 한복을 그대 로 입는 것은 자연스럽지 못하다. 이처럼 전통 한복 은 행사의 성격과 착용자의 역할에 따라 착용 기준이 달라지기 때문에 다양한 한복이 필요하지만, 착용빈 도가 낮아 매번 구입하는데 부담을 느낀 소비자들의 요구에 의해 한복 대여업이 시작되었다(Park, 2005).

한복 대여 업체의 현황과 전망에 대해 연구한 $\mathrm{Lim}$ and $\operatorname{Kang}(2001)$ 에 따르면, 한복 대여 업체의 $80 \%$ 가 전통한복만 대여하고, 주로 여자 한복을 대여하였다. 대여 목적으로는 회갑과 칠순 잔치 참석, 가족 결혼 식 등 축하 행사와 본인결혼식, 돌잔치 등의 행사 참 여 등으로 나타났다. 한복 대여업에 대한 다른 연구 (Kim, 2016; Park, 2005)들도 예복으로 입는 고급 전 통한복 대여 업체를 연구 대상으로 삼고 있다. 이들 한복 대여업에서는 주로 실크와 같은 고급 소재와 가 족 행사에 적합한 고급스러운 디자인, 높은 가격대를 형성하는 전통한복을 대여하고 있다. 이에 본 연구에 서는 이처럼 가족 행사를 위한 대여 한복을 의례용 한복으로 명명하고자 한다.

그런데 최근 관광지를 중심으로 나타난 대여 한복 은 기존의 의례용 한복과 다른 양상을 보이고 있다. 전주 한옥마을에는 방문객들이 한복을 입고 관광할 수 있도록 수십 벌의 한복을 구비하고, 짧게는 1 시간 부터 길게는 하루 종일 한복을 대여해주는 업체들이 등장했다(Kim, 2016). 이는 기존의 의례용 전통 한복의 대여 기간이 일반적으로 2 박 3 일인 점(Lim \& Kang, 2001)과 다르고, 대여 비용도 1 2만 원대로 저렴하 다. 대여 품목도 여자 한복에 한정되지 않고, 남녀 커 
플 한복, 가족 한복 등으로 다양하다. 또한 역사 드라 마에 등장했던 한복을 흉내 낸 한복이나 곤룡포와 같은 특별한 전통 한복까지 대여되는 등 기존의 대여 한복 과는 다른 점을 보이고 있다. 이러한 한복은 독특한 체 험을 목적으로 하고 있기 때문에, 본 연구에서는 체 험용 한복으로 명명하여 의례용 한복과 구분하였다.

이에 가족 행사를 위해 대여하는 의례용 한복과 함 께 관광지에서 대여되고, 이는 체험용 한복을 아우르 는 연구가 필요하다고 생각된다. 특히 체험용 한복 대여는 최근 시장에 나타난 현상으로서 관련된 연구 가 없기 때문에 시장과 소비자 등 다양한 측면에서의 연구가 필요하다고 생각된다.

\section{Methods}

본 연구는 지난 10 년 동안 대여 한복에 나타난 변 화를 알아보는 것을 목적으로 시장 상황을 반영하는 인터넷 뉴스에 대한 내용 분석과 함께 소비자를 대상 으로 한 심층 면접을 이용한 질적 연구를 중심으로 전개되었다. 연구 방법으로 질적 연구를 선택한 이유 는 첫째, 본 연구의 대상인 두 가지 유형의 대여 한복 에 대한 관련 연구가 적기 때문이고, 정량적 연구를 수행하기에 앞서 대여 한복에 대한 기초 지식을 얻기 위한 탐색적 수준의 연구로 설계되었기 때문이다.

먼저 대여 한복 소비의 변화를 시장 측면에서 알아 보기 위해, 2006년과 2016년 사이에 나타난 대여 한 복 관련 인터넷 자료를 수집하여 분석하였다. 사람들 은 새로운 뉴스를 접할 때, 텔레비전이나 종이신문, 인터넷 등을 사용한다. 2013년도 미디어별 뉴스이용 현황(Korea Press Foundation, 2013)에 따르면, 사람 들이 새로운 뉴스를 접하는 채널은 텔레비전(53.6\%) 이 절반 이상을 차지하고, 고정형 인터넷(15.2\%)과 이동형 인터넷(14.3\%), 그리고 종이신문(11\%) 등의 순서로 나타나, 뉴스 이용에 있어서 인터넷의 중요성 을 확인할 수 있다. 인터넷 뉴스의 재사용성과 연계 된 인터랙션 연구(Hwang, 2015)에 따르면, 인터넷 뉴 스는 즉시성, 하이퍼텍스트성, 상호작용성, 멀티미디 어적 특성 등이 있다. 이 중 단어 하나를 입력하면 관 련된 모든 파일을 검색할 수 있는 하이퍼텍스트성과 정보가 데이터로 저장되어 원할 때 검색할 수 있다는 특성은 본 연구에서 살피고자 하는 특정 시기의 사회
적 변화를 파악할 수 있는 근거로 생각되어 연구 자 료로 선택하였다.

인터넷 뉴스를 살필 수 있는 경로는 언론사 사이트 와 포털 사이트로 나눌 수 있는데, 포털 서비스의 인 터넷 뉴스 서비스를 이용한 뉴스 획득의 경우가 많다 는 연구 보고(Korea Communications Agency, 2014) 에 따라 국내 포털 검색 사이트를 비교하여 선택하였 다. $\mathrm{PC}$ 와 휴대폰 사용 행태를 조사하여 기본 자료를 제공하는 코리안 클릭에 따르면, 2016년 국내 포털 중 검색시장 점유율 순위는 네이버, 다음, 구글 순이 었다. 이 중 네이버는 PC $93.4 \%$, 모바일 53.1\%를 차지 하고 있어, 다른 사이트에 비해 압도적인 차이를 보이 고 있었다. 인터넷 뉴스 검색 측면에서 네이버와 다 음의 뉴스 검색 시스템을 살펴보았는데, 검색 화면의 구성과 검색 범위에서 차이가 있었다. 다음 뉴스는 키 워드 입력 후 기간 설정과 언론사 선택만 가능한 데 비해, 네이버 뉴스는 뉴스의 종류, 키워드 검색 범위, 기간 설정 등이 가능했고, 상세검색을 통해 사용자가 원하는 뉴스를 좀 더 구체적으로 확인할 수 있었다. 이러한 구체적 검색 방법을 이유로 본 연구에서는 네 이버를 인터넷 뉴스 검색 엔진으로 결정하였다.

검색 기간은 2006년과 2016년 1월 1일 12월 31일 까지로 지정한 후, ‘대여 한복'을 키워드로 사용하였 다. 검색 단어가 기사의 제목이나 내용에 포함된 뉴 스를 검색하여 목록화한 후, 제목을 중심으로 유사한 뉴스들을 분류하였다. 그런 다음 반복적으로 뉴스의 내용을 읽고 분석하여 그룹을 묶을 수 있는 단어들을 선정하고 확인하였다. 이러한 과정 중에 개인적인 의 견과 정책적인 내용을 안내하는 기사는 제외하였다. 그러나 바이럴 마케팅의 일환인 상업적인 기사는 한 복 대여에 관심이 있는 소비자를 대상으로 작성되었을 것으로 생각되어 그 주제에 따라 ‘웨딩박람회', ‘웨딩 업체', ‘한복업체', ‘스튜디오' ‘돌잔치' 등으로 분류 하고, 순수한 '대여 한복'에 대한 인터넷 기사와는 구 분하고자 하였다. 이를 통해 관련 뉴스 기사의 양적 확대 측면을 확인하는 단계에서는 최대한 많은 자료 를 확보하고자 노력하였고, 기사의 내용을 살펴보는 단계에서는 홍보성 기사를 제외하고, '대여 한복'에 대한 내용을 비교 분석하였다.

두 번째, 대여 한복 소비의 변화를 소비자 측면에 서 알아보기 위해 심층면접을 실시하였다. 면접 내용 
은 2006년 연구에서 사용된 문항을 기본으로 재설계 하였다. 당시 면접에 사용한 문항은 의류 대여 경험이 있는 여성 소비자 5명을 대상으로 2006년 4월에 실시 한 기초조사에서 추출된 내용을 바탕으로 연구자와 전문가가 각각 검토한 후 토의를 거쳐 결정하였다. 구체적인 질문 내용은 의류 대여 경험, 대여 목적, 결과 만족도 등 대여에 대한 내용과 의류관여도, 의류 구 매 경로 등 의류 소비에 대한 내용으로 구성되었다.
그러나 본 연구는 2006년에 실시된 의류 대여 소비에 대한 소비자 조사와 달리, 한복 대여 소비자에 대한 탐색적 연구이기 때문에 질문 내용을 기존 의류 대여 경험과 한복 대여 이유의 2개 문항으로 한정하였고, 이를 전문가와 함께 검토한 후, 2016년 본 연구에 적 용하였다. 모든 면접은 사전에 면접자에게 양해를 구 해 녹음하고 분석에 사용하였다. 2006년과 2016년의 면접 대상자 특성은〈Table 1〉과 같다.

$<$ Table 1> Feature of interviewee

\begin{tabular}{|c|c|c|c|c|}
\hline \multicolumn{5}{|c|}{ 2006's } \\
\hline No. & $\begin{array}{l}\text { Demographic } \\
\text { characteristics }\end{array}$ & Rental user & Rental purpose & Rental channel \\
\hline 1 & 40's unmarried woman & Self & Parent's 70th birthday party & Rental shop \\
\hline 2 & 40's married woman & Self & Parent's 70th birthday party & Rental shop \\
\hline 3 & 30's married woman & Self & Child's 1'st birthday party & Internet searching \\
\hline 4 & 30's married woman & Self \& baby & Child's 1st birthday party & Internet searching \\
\hline 5 & 30's married woman & Self \& baby & Child's 1'st birthday party & Hanbok shop \\
\hline 6 & 20's married woman & Self & Child's 1'st birthday party & Internet searching \\
\hline 7 & 30's married woman & Self & Sister's marriage & Internet searching \\
\hline 8 & 30's married woman & Self & Class & Internet searching \\
\hline 9 & 20's married woman & Self & Wedding photo & Wedding photo package \\
\hline \multicolumn{5}{|c|}{ 2016's } \\
\hline No. & $\begin{array}{l}\text { Demographic } \\
\text { characteristics }\end{array}$ & Rental user & Rental purpose & Rental channel \\
\hline 1 & 30's married woman & Self & Brother's marriage & Internet searching \\
\hline 2 & 30's married woman & Self & Sister's marriage & Internet searching \\
\hline 3 & 40's married woman & Self & Sister's marriage & Hanbok shop \\
\hline 4 & 30's married woman & Self \& baby & Child's birthday party & Internet searching \\
\hline 5 & 30's married woman & Self & Wedding photo & Wedding photo package \\
\hline Team 1 & Family & $\begin{array}{l}\text { Grandmother, } \\
\text { mother, daughter }\end{array}$ & Experience & Rental shop \\
\hline Team 2 & Family & $\begin{array}{l}\text { Father, mother, } \\
2 \text { children }\end{array}$ & Experience & Rental shop \\
\hline Team 3 & Family & $\begin{array}{l}\text { Father, mother, } \\
2 \text { children }\end{array}$ & Experience & Rental shop \\
\hline Team 4 & Family & $\begin{array}{l}\text { Father, mother, } \\
2 \text { children }\end{array}$ & Experience & Rental shop \\
\hline Team 5 & Couple & 1 man, 1 woman & Experience & Rental shop \\
\hline Team 6 & Couple & 1 man, 1 woman & Experience & Rental shop \\
\hline Team 7 & Friends & 3 girls & Experience & Rental shop \\
\hline Team 8 & Friends & 3 boys & School event (festival) & Rental shop \\
\hline
\end{tabular}


질적 연구에서 표본 수의 적정성은 연구의 목적에 적합한 답이 얻어졌는가가 기준이 되기 때문에(Merriam \& Tisdell, 2015), 대상자의 숫자를 사전에 정하지 않 고 시작하였다. 2006년의 심층 면접 자료는 의류 대 여 소비에 대한 연구(Shim, 2007)에서 한복에 관한 내용이 담긴 부분만 원 자료를 기준으로 추출하여, 총 9명의 면접 자료를 본 연구에 이용하였다. 2016년 의 심층 면접 대상자는 대여 한복을 의례용 한복과 체험용 한복으로 구분한 후, 각 한복에 대해 면접 대 상자를 모집하였다. 연구 참여자와의 면접은 2016년 9 월 10 일부터 10 월 2 일 사이에 이루어졌다. 의례용 한복은 면접 대상자의 집 또는 카페 등에서 실시하였 고, 면접 시간은 약 20 분 내외였다. 연구 참여자는 연 구자 주변의 지인 중 2016년에 결혼식이나 돌잔치 등 가족 행사에 착용하기 위해 한복을 대여한 경험이 있 는 사람을 중심으로 소개 받아 진행하였고, 5 명의 면 접 사례가 이전 연구와의 비교에 충분하다고 판단되 어, 면접을 중단하였다. 체험용 한복은 전주 한옥마을 에서 한복을 체험하고 있는 사람들을 즉석에서 섭외 하여 진행하였고, 면접 시간은 20 30분 정도 소요되 었다. 이 부분은 이전 연구에서는 나타나지 않았던 새 로운 대여 소비 형태이기 때문에, 좀 더 많은 면접을 진행하기 위해 노력하였다. 체험용 한복은 주로 여러 명이 함께 착용하는 경우가 많았기 때문에, 의례용 한복에 비해 면접시간이 상대적으로 길었다. 그리고 가족이나 연인 그리고 친구 등 다양하게 구성된 팀을 살필 수 있었지만, 면접 내용에서 유사한 내용이 반 복적으로 확인되면서 총 8 팀까지 진행한 후 면접을 중단하였다.

자료의 분석에는 면접 상황에서 기록한 요약자료, 녹취 내용을 옮긴 전개자료, 자료 수집 기간 중 느낀 점들을 적은 작업 기록이 모두 포함되었다. 자료의 분 석 방법은 개방적 코딩방법(Giorgi, 1985/2004)을 사 용하였는데, 먼저 반복해서 녹취 내용을 듣고, 녹취록
을 읽어 전체적인 느낌을 얻고, 녹취된 자료를 여러 번 읽고 의미 있는 구절이나 문장을 표시한 후, 반복적으 로 나타나는 주제들을 찾아 개념화하였다. 마지막으 로 추출된 개념들을 재검토하면서 핵심 주제에 맞는 개념을 찾는 과정을 반복하였다. 그리고 객관적 자료 분석 과정에 대해 질적 연구 전문가의 확인을 거쳐, 연 구 결과의 타당성을 확보하였다. 연구 결과 제시에서 는 참여자를 모두 번호로 처리하여 익명성을 보장하 고, 체험용 한복에 대한 결과 제시는 팀 번호와 함께 주도적으로 응답한 팀원에 대한 설명을 덧붙였다.

\section{Results and Discussion}

\section{Change in market}

\section{1) Quantitative change}

한복 대여 관련 뉴스를 분석한 결과, 2006년과 2016 년 사이에는 뉴스의 양적 변화가 뚜렷하게 나타났다. 2006년에는 총 41개 검색된 데 비해 2016년에는 총 1,088 건이 검색되었다. 그러나 이 중 관련성이 적은 정책적인 내용을 제거하고, 한복 대여가 중요하게 언 급되는 내용을 중심으로 정리한 결과, 총 912 개의 기 사가 분석에 이용되었다. 뉴스 내용은 대여 산업과 한복 산업의 변화를 다룬 트렌드에 관한 내용과 의례 용 한복과 체험용 한복으로 구분되는 한복에 대한 내 용으로 구분되었다. 이를 정리하면 〈Table 2〉와 같다.

의례용 한복에 관한 뉴스는 2006 년 20 개의 기사가 2016년에는 278개로 10 배 이상의 증가하였다. 그러 나 2016년의 기사의 경우, 제목을 기준으로 분류한 결과, 결혼식에 관한 기사(36건)나 돌잔치 관련 기사 (23건) 외에, 웨딩 박람회 홍보(69건), 특정 웨딩 업체 홍보(119건), 한복 업체 홍보(12건) 등에 대한 기사가 다수 포함되어 인터넷 뉴스가 홍보 수단으로 사용되 고 있음을 알 수 있었다. 홍보성 기사 중 특히 웨딩업

<Table 2> Internet news related to Hanbok rental

Frequency (\%)

\begin{tabular}{c|c|c|c|c|c}
\hline \multirow{2}{*}{ Contents } & \multicolumn{2}{|c|}{ Related to trend } & \multicolumn{2}{c}{ Related to Hanbok } & \multirow{2}{*}{ Total } \\
\cline { 2 - 5 } & Rental & Hanbok & Ceremonial & Experiential & $41(100)$ \\
\hline 2006 & $13(32)$ & $8(20)$ & $20(49)$ & & $912(100)$ \\
\hline 2016 & $35(4)$ & $20(2)$ & $278(30)$ & $579(63)$ & 912 \\
\hline
\end{tabular}


체와 웨딩박람회에 대한 기사에서는 스튜디오 촬영, 드레스, 메이크업을 묶어 말하는 ‘스드메' 패키지에 한복을 포함하여 제공한다는 내용이 많았다. 이러한 인터넷 뉴스 기사를 통해 결혼식 관련 업체에서 주도 적으로 의례용 한복 대여에 관여하고 있다는 것을 알 수 있었고, 이는 웨딩업체에서 한복을 일회성 대여 상 품으로 다루면서 한복의 위상이 악화되고 있다는 Yoon (2012)의 주장과 통하는 결과였다.

체험용 한복은 2006년에는 관찰되지 않았던 대여 한복 유형이지만, 2016년의 기사에서는 $63 \%$ 에 해당 하는 579 건의 뉴스가 작성되어 가장 많은 부분을 차 지하였다. 이 중 젊은이들의 한복입기 붐과 관련하여 작성된 기사(104건)를 제외한 475건의 기사는 각종 지방 자치 단체에서 관광사업 활성화를 위해 계획한 정책적 내용이나 관광공사에서 안내하는 관광지 소 개 등과 연계된 홍보성 기사 등이 많았다. 또한 관광 공사에서 관광지를 알리는 기사나 지역 행사를 소개하 는 내용도 많았고, 특이하게도 고궁에 무료입장이 가 능한 한복을 대여해주는 서비스를 패키지 상품으로 구성하여 호텔을 홍보하는 내용도 있어 흥미로웠다.

의례용 한복과 체험용 한복 모두 2006년에 비해 뚜렷한 양적 증가를 보였지만, 대부분 홍보성 기사여 서 내용을 살펴보는 과정에는 포함하지 않았다.

\section{2) Contents change}

2006년과 2016년의 인터넷 뉴스 검색 결과에서 홍보 성 기사를 제외한 뉴스를 중심으로 내용의 변화를 살 펴보았는데, 한복 트렌드에 대한 내용과 의례용 한복에 대한 내용 그리고 체험용 한복에 대한 내용으로 정리 하였다. 그리고 뉴스 제목과 내용에 홍보성 내용을 포함하지 않은 기사를 1 2개 정도 선택하여 내용을 분석하였다. 뉴스 기사의 숫자가 이처럼 적은 이유는 뉴스의 제목과 내용 중 업체의 이름이 하나라도 언급 된 경우는 모두 분석에서 제외하였기 때문이다.

\section{(1) Changes in Hanbok trend}

한복의 트렌드에 대한 내용을 다룬 기사에서는 2006 년에 한복업계의 지속적인 어려움 속에 한복 대여점 으로 전환하는 업체가 늘고 있다는 내용이 소개된 데 비해, 2016년에는 한복입고 세계를 여행하는 젊은이 나 일상생활 속에서 한복을 즐겨 입는 젊은이를 소개
하는 등 긍정적인 내용이 눈에 띄었다. 그런데 기사 내용 중에는 생활 속에서 착용되는 신한복에 대한 내 용과 대여 한복에 대한 내용이 혼재되어 있어서 추후 연구를 통해 자세한 분석이 필요하다고 생각되었다.

"설빔 '한복은 없다'. 폐업 속출, 대여점 전환" (2006.01.26. 경향신문)

“한복입고 어디까지 가봤니?” (2016.08.14. 여성신문) “한복, 일상복으로도 손색없어요” (2016.10.25. 뉴시스)

\section{(2) Ceremonial Hanbok}

의례용 한복은 크게 결혼식용 대여 한복과 돌잔치 용 대여 한복에 대한 기사로 구분할 수 있었다.

먼저 결혼식용 대여 한복에 대한 기사에서는 2006 년에는 결혼식장이나 드레스 선택부터 주택장만에 이르기까지 전체적인 결혼 준비에 대해 다룬데 비해, 2016년의 기사에서는 주로 신부 한복을 비롯한 혼주 의 한복 등을 경제적으로 준비할 수 있는 방법과 한 복을 포함한 '스드메' 패키지에 대한 내용이 주를 이 루었다. 이를 통해 2006년에는 전체적인 결혼 과정에 서 대여 한복이 간단하게 소개되었다면, 2016년에는 대여 한복에 신부 한복뿐 아니라, 혼주 한복까지 포 함되어 다양한 결혼식용 한복이 대여되고 있음을 알 수 있었다.

“봄날의 신부, 알뜰 결혼준비 방법과 이색 예식 법” (2006. 03. 20. 세계일보)

“화사 우아한 맵시 ‘눈길이 절로 가네”” (2006. 09. 30. 부산일보)

"양가어머니한복 대여로 저렴하게 해결 가능해졌 다" (2016. 01. 20, 넥스트데일리)

“예비 신혼부부를 잡아라.” (2016. 08. 03. 아시아 투데이)

아이 돌잔치를 위한 대여 한복 기사에서도 내용 변 화가 있었다. 2006년에는 스스로 준비하는 돌잔치를 위한 안내가 주제였다면, 2016년 기사에서는 스스로 준비하는 돌잔치의 어려움 등에 대한 내용을 보여주 고 있다. 그리고 '다문화가족 자녀를 위한 합동돌잔 
치' 등 지역사회의 행사에서 아이들을 위한 한복을 대여해 준 것을 다룬 기사도 있었다. 특히 다문화 가 족 자녀를 위한 합동 돌잔치의 경우, 결혼을 통해 우 리나라에 정착한 외국인들이 적응하는데 도움을 줄 수 있는 방법으로 생각되었다.

"알뜰하고 꼼꼼한 돌잔치 준비 10단계” (2006. 04. 20. 레이디경향)

“우리 아이 설빔 똑똑하게 마련하자” (2006. 01. 18. 경향신문)

“밤샘 준비.. 결혼식보다 더 힘든 ‘돌잔치’” (2016. 01. 05. 해럴드 경제)

"다문화 가족 자녀 합동돌잔치” (2016. 10. 05. 강 원일보)

\section{(3) Experiential Hanbok}

체험용 한복에 대한 뉴스 기사는 2006년에는 검색 되지 않았던 부분으로, 주제별로 정리한 결과, 지방자치 단체나 행사 그리고 패키지 상품 등에 관한 홍보성 기사 를 모두 제외하면 젊은이들의 문화를 소개하는 기사 가 124 건 검색되었다. 기사의 숫자는 많지만 내용이 유사하여, 대표적인 기사 2 가지만 언급하고자 한다.

"나는 한복 스타일.. 젊은이들, 한복체험 '붐”” (2016.09.21. MBN)

"단오날 '한복입고 폴짝', 10 대 신놀이문화 '한놀 족”” (2016.06.09. 시크뉴스)

젊은이들의 체험 문화로 대여 한복을 다룬 뉴스 기 사는 10 20대들이 최근 궁이나 한옥마을 등에서 한 복을 착용하고 사진을 찍어 SNS에 올려 서로 소통하 는 문화에 대해 보여주고 있다. 이러한 뉴스에서 젊 은이들은 전통한복 착용을 하나의 놀이문화로 받아 들여 즐기고 있는 모습이다. 이는 앞서 살핀 의례용 한복이 필요에 의해 선택되는 것과 비교할 때, 다른 욕구 차원에서 한복 대여를 선택하는 것으로 파악되 며, 소비자 행동 측면에서 이에 대해 추가적인 연구 가 필요하다고 생각된다.

그리고 체험용 한복에 대한 기사 중 마땅한 규제가 없다는 내용과 체험용 한복의 열풍이 실제 한복 산업
에는 영향을 미치지 못하고 있다는 비판적인 의견의 뉴스도 있었다. 특히 규제없이 난립한 한복 대여점의 문제점에 대한 기사를 통해, 한복 대여업의 심각성을 알 수 있었다. 이에 관광지에 위치한 체험용 한복 대 여점에 대한 실태 조사와 함께 적절한 기준에 대한 연구가 필요할 것으로 생각된다.

“전주 한옥마을 한복대여점 난립 ‘출혈경쟁”, (2016.05.11. 전민일보)

“한복 열풍, 고궁 안에만 불더군요.” (2016.06.02. 서울신문)

\section{Change in consumer}

대여 한복에 대한 소비자의 측면의 변화를 살펴보 기 위해 심층 면접을 실시하였다. 2006년에는 아직 체험용 한복이 시장에 소개되지 않았기 때문에, 당시 에는 의례용 한복에 대한 조사만 실시되었다. 2016년 에는 인터넷 뉴스의 내용을 분석하여 시장에 두 가지 대여 한복이 존재한다는 것을 확인하고, 의례용 한복 과 체험용 한복을 대여한 경험이 있는 소비자들을 각 각 모집하여 면접하였다. 따라서 의례용 한복의 경우 2006년과 2016년의 면접 자료를 비교하여 정리하였 고, 체험용 한복의 경우 2016년의 자료를 단독으로 정리하였다.

\section{1) Ceremonial Hanbok}

의례용 한복을 대여한 소비자들의 대여 목적은 돌 잔치나 결혼식 그리고 칠순잔치와 같은 가족행사가 많았다. 이들이 한복 대여 시 원하는 바가 무엇인지, 추구혜택에 변화가 있는지 알아보기 위해, 2006년의 면접 자료와 2016년의 면접 자료를 비교한 결과, 내 용 면에서 뚜렷한 차이가 관찰되지 않았고, 적합성, 경제성, 과시성, 유행성, 특수성 등의 추구혜택이 추 출되었다. 이는 의례용 한복이 특별한 상황에서 유행 을 고려하고 자신의 신분을 보여주기 위해 착용해야 하는 의복임을 보여주는 결과이며, 이러한 특성들이 의례용 한복의 소비에 있어 경제적인 대여 소비를 선 택하게 하는 원인으로 생각되었다.

\section{(1) TPO (Occasion suitability)}

적합성은 특별한 상황이나 역할에 적합한 의류를 
원한다는 내용으로, 면접 대상자들이 가장 많이 언급 한 한복 대여 추구혜택이었다. 의례용 한복은 가족 결혼식, 자녀의 돌잔치나 부모님의 생신잔치 등의 가 족 행사와 교회에서의 행사 등 목적이 뚜렷한 행사에 참석하기 위해 착용하기 때문에, 한복의 선택에 있어 서 $\mathrm{TPO}$ 에 적합한가가 중요한 것으로 나타났다. 이를 통해 소비자들은 전통한복이 특별한 목적성을 갖고 있다고 느낀다는 점을 파악할 수 있었고, 따라서 소 비자들에게 보다 큰 만족도를 주기 위해서는 좀 더 격식에 맞는 갖추어진 느낌을 주는 한복의 개발이 요 구된다.

"우리 시누이 결혼식에 다들 한복을 입자고 하더 라고요. 가족들은 통일감있게 입자고 했는데, 똑 같은 양장은 좀 이상하잖아요. 결혼식에 입기도 그렁고, 그래서 모두 한곳에서 한복을 대여하기 로 했어요.” (2006 - 7)

"막내 시누이 결혼식에 온 가족이 단체로 한복을 입기로 했어요. 그것도 의미있을 것 같다고. 남자 는 빼고 여자들만요. 시누나 올케 구분없이 그냥 뜩같은 걸로 빌려 입었어요. 단체로." (2016 - 2) "동생이 결혼하는데, 엄마가 옷에 신경 좀 쓰고 오 라고 하시더라구요. 신부만 이뻐면 되는 건데, 싶 긴 했는데 엄마가 그렇게 말씀하시니 무시할 순 없고. 그래서 고민하다가 한복을 빌렸어요. 마땅 히 결혼식에 입고 갈만한 옷이 없더라구요. 그냥 하객도 아니고, 신부 언닌데. 어쨌든 엄마 말을 신경쓰다 보니까 한복만한 게 없더라구요." (2016 - 3)

“남동생 결혼식에 꼭 한복을 입고 싶었어요. 그런 데 제가 가지고 있는 건, 시집올 때 입었던 것 밖 에 없었거든요. 노란 저고리에 분홍치마. 딱 보면 신부 한복. 그걸 입을 순 없잖아요. 그래서 어쩔 수 없이 대여했어요." (2016 - 1)

"한복은 돌잡이 할 때 꼭 입어야 하니까, 돌잔치 때, 우리는 정장 입고 애도 원피스 입었고요. 돌 잡이는 안할 수 없잖아요. 사진도 남겨야 하고, 중요한 행사니까. 그래서 한복은 대여해서 돌잡 이 할 때만 입었어요." (2006 - 3)

"아버지 칠순잔치가 하루 행사였는데, 격식을 차 려서 행사를 할 수 있는 상황이 아니었어요. 그래
서 아는 식당에서 잔치를 하기로 했는데, 각자 한 복을 맞춰 입기 뭐해서 대여해서 입었어요. 언니 아는 한복집에서 같은 디자인으로 대여했죠. 있 더라고요. 단체 한복이. 신기했어요." (2006 - 1) “자주 입어요. 한복. 교회에서 가끔 순번에 맞춰서 안내를 하는데요. 그땐 꼭 한복을 입어요. 난 그 게 좋던데요. 뮌가 갖춰 입은 것 같고 해서요. 보 통 때는 제 한복 입는데, 딱 한번 작년 겨울에 중 요한 행사를 할 땐 빌려 입었어요." (2016 - Team 1 , 할머니)

\section{(2) Economy}

경제성은 꼭 필요한 의복이라도 너무 비싼 경우에 는 구매보다는 필요한 목적에 맞추어 대여한다는 의 견이었다. 경제성에 대한 응답 부분은 앞서 살펴본 '상황 적합성'과 함께 제시되는 경우가 많았는데, 이 는 상황에 맞도록 의복은 갖추어 입되, 소비는 합리 적인 대여를 선택한다는 것으로 해석되었다.

전통한복의 의례적 의미가 강해지는 상황에서, 경 제적인 이유로 한복 대여를 선택하는 소비자들은 더 욱 증가할 것으로 생각된다. 최근에는 신랑, 신부의 한복뿐만 아니라, 혼주의 한복까지도 한복 대여 패키 지 상품에 포함되는 추세가 나타나고 있어, 상황적합 성과 경제성을 고려한 다양한 의례용 한복 상품 개발 이 필요하다.

"어차피 한 번만 입을 건데, 사기에는 아깝고 차라 리 대여하는 게 나을 것 같아서 빌렸어. 한복이 한두푼 하는 것도 아니고 새로 맞춰 입기는 너무 비싸더라. 그 돈이면 차라리 양장 한 벌을 더 사 서 입겠다 싶어서, 다들 맘에 드는 옷 한 벌씩 사 고 한복은 빌려 입었지." (2006 - 2)

“사진만 찍고 말 건데요. 굳이 살 필요가 있나요? 그건 낭비같아요. 요즘은 시댁에 갈 때도 누가 한 복입고 가나요. 그래서 그냥 사진찍을 때, 그때만 잠깐 입었어요. 패키지에 있는 상품이었어요." (2006 - 9)

"하루 종일 웨딩사진을 찍었는데요, 그때 드레스 도 그렁고 한복도 그렇고 잘 준비해주더라구요. 저희는 예복도 안 맞칬어요. 한복도 안 맞추고." (2016 - 5) 
“처음에는 사줄 생각이었어요. 그래서 알아보기도 많이 하고 그랬는데, 한복은 너무 일회성이고 애 기들이 명절 때 아니면 한복 입을 일이 없잖아요. 그리고 요즘에는 돌잔치 할 때, 정장이랑 한복을 함께 입히거든요. 정장도 한복도 자주 입지 않으 니까, 저희 껀 사고 애기 껀 빌렸어요. 필요한 걸 모두 사줄 순 없잖아요.” (2006 - 5)

"이건 특별한 거니까 사주고 싶었어요. 그런데 너 무 비싼 거예요. 돌 복을 두 번 입을 것도 아니고, 한참을 고민하다가 결국 빌렸어요.” (2016 - 3) “결혼준비에서 다른 비용도 만만치 않은데, 한복 은 정말 비싸더라고요. 그리고 매니저가 제안해 준 “스드메” 패키지에 한복도 포함되어 있었구 요. 그래서 별 고민없이 그 패키지를 선택했죠 무, 경제적이니까요." (2016 - 4)

\section{(3) Exhibition}

과시성은 특별하게 행사에서 돋보이고 싶은 마음 으로 대여 한복을 이용하는 경우였다. 의례용 한복은 행사에서 주로 착용하는 한복이기 때문에 행사의 주 인공인 경우에는 과시성을 중요하게 생각하는 경우 가 있었다. 상황적합성은 $\mathrm{TPO}$ 에 맞추어 의복을 갖춘 다는 개념이지만, 과시성은 자신이 주인공임을 강조 하기 위해 특별히 한복을 선택하는 경우여서 구분하 였다.

“내 평생 '당의'를 입을 기회가 몇 번이나 있겠어 요. 돌잔치 주인공은 물론 내 아들이지만, 나도 주인공이 되는 거잖아. 주최는 나니까. 그래서 그 때밖에 못 입는 옷을 찾았어. 한번 밖에 없는 돌 잔치니까 특별하게 하고 싶어서 당의를 입었지."

(2006 - 4)

"요새는 돌잔치 패키지에 한복도 들어가던데요? 한복 고를 때는 솔직히 애기 옷보다는 제가 예뻐 보이는 옷으로 골랐어요. 그렇잖아요. 애기야 어 차피 뮐 입혀도 귀여우니까. 그래서 그냥 제 맘에 드는 걸로 골랐어요. 제 꺼 고르고 나니까 남편 꺼는 세트로 왔어요. 비녀부터 버선이랑 빨간 신 발까지. 돌잡이하고 사진찍을 때 되니까, 업체 사 람이 풀세트로 입혀주던데요. 그날 왕비 된 거 같 았어요." (2016 - 4)

\section{(4) Trendy}

유행성은 전통한복의 스타일에 변화가 존재하여 착용빈도는 낮지만, 유행에 따르기 위하여 대여를 이 용한다는 응답이었다. 이러한 내용을 통해 면접 대상 자들이 전통한복에도 유행이 있다고 느낀다는 점을 알 수 있었다. 그런데 Kim, Y. M.(2016)은 한복 대여 전문점에 대한 연구에서 대여 한복 시장에 초기 참여 업체들 중 일부는 한복업계의 불황으로 인해 누적되 었던 제고원단을 소진시키려는 차원에서 한복대여업 에 참여한 경우도 있음을 지적한 바 있다. 대여 한복 산업이 활성화시키기 위해서는 새로운 디자인을 지 속적으로 소개하는 노력이 필요할 것이다.

“요즘 컬러풀하게 입는 잔치용 한복은 유행이 있 더라고요. 그러다 보니까. 몇 년에 한번 입자고 그때마다 맞출 수가 없잖아요. 옛날에 지은 한복 이 비싼 거라고, 시집올 때 입었던 꽃분홍색 치마 를 입고 나갈 수도 없고, 유행 맞춰 맨 날 해 입을 수도 없고, 그래서 필요할 때 빌려 입어요." (2006 - 2)

“전 한복을 좀 즐겨 입는 편인데요. 가만 보니까 한복에도 유행이 있어요. 몇 년 전엔 저고리가 길 었거든요? 그런데 요즘엔 그런 거 잘 안 입어요. 얼마 전에 별 생각없이 차 모임에 긴 저고리 입고 나갔는데, 저만 입었더라구요. 솔직히 민망했어 요. 자주 입는 건 아닌데, 그래도 입을 때 유행이 신경 쓰이긴 해요. 그 일 뒤론 중요한 일이 생기 면 일단 유행부터 살펴요. 내 꺼를 입고 갈지 말 지 결정하려구요. 시간이 안 되면 빌려 입으면 되 지요." (2016 - Team 3, 엄마)

\section{(5) Exceptionality}

2006년의 면접 내용 중에는 수업 시간에 활용하기 위해 한복을 대여했다는 내용이 있었다. 초등학교 수 업 시간에 실제 학생들이 착용해 보기 위해 제작된 혼례복을 대여한 경우였는데, 교구로 특별히 제작된 한복이었다. 이에 대한 내용은 2016년에는 면접 대상 을 구할 수 없어 포함되지 않았지만, 추후 연구에서 는 교구로 제작된 한복을 포함한 다양한 한복에 대한 연구를 추가해야 할 것으로 생각된다.

"전 초등학교 선생님인데요. 수업 시간에 전통 혼 
례 가르치면서 한복을 빌려봤어요. 일반 한복은 아니구요, 아이들 크기로 제작된 혼례복이요. 원 삼이랑 남자꺼랑. 옆에 선생님이 알려주셔서 인 터넷 통해서 빌렸어요. 교구 만드는 업체였던 거 같은데. 사이즈가 애매하긴 했는데, 애들이 굉장 히 재미있어 했어요." (2006 - 8)

\section{2) Experiential Hanbok}

체험용 한복 대여에 대한 면접 내용은 의례용 한복 과 많은 차이를 보여, 소비자들이 두 가지 한복에 대 해 다르게 인식하고 있다는 점을 알 수 있었다. 그리 고 체험용 한복으로 대여되는 한복에는 그 동안 일반 인에게는 많이 노출되지 않았던 곤룡포나 철릭 등도 포함되어 있었는데, 우리나라 전통한복임에도 불구하 고, 일반 소비자들은 그 다양성을 모른다는 사실을 알게 되었다. 또한 전통 한복에 대해 상당히 고정적 인 이미지를 가지고 있어서, 동일한 치마와 저고리라 고 할지라도 ‘황진이 한복' 또는 ‘드라마 의상’이라고 표현하는 응답을 보였다. 이러한 사실을 통해 면접 대상자들이 갖고 있는 고정적 이미지를 없애고, 다양 한 전통한복을 개발하여 알릴 수 있는 방안을 찾아야 할 것으로 생각되었다.

\section{(1) Uniqueness}

소비자들은 체험용 한복을 일반적인 한복과 다르 다고 느낀다고 언급했다. 특히 평소에 접하지 못하는 풍성하고 화려한 스타일과 원단들, 그리고 드라마나 영화 등에서 봤던 의상이라고 생각하는 경우도 있어 특이성이라고 명명하였다.

“사람들이 이걸 ‘테마 한복’이라고 부르더라고요. 뮌가 좀 다른 거 같아요. 뭐라고 말하기는 애매한 데, 아무튼 보통 때 밨던 한복이랑 비슷한 데 또 좀 다른 거 같아요. 드라마에서 봤던 거랑 비슷한 거 같기도 하고. 어쨌든 특이하더라구요. 여기서 만 볼 수 있는 거 같아요." (2016 - Team 3, 엄마) "평소에도 한복 자주 입는 편인데, 이런 건 안 입 어봤어요. 굉장히 화려해요. 원단도 화려하고요. 평상복으로는 못 입을 거 같아요. 이거 드라마에 나왔던 의상 아닌가요? '황진이' 에서 본 거 같은 데. 드라마 의상이잖아요.” (2016 - Team 1, 엄마)
"평상시에 입기에는 너무 불편해요. 하지만, 여기 에선 괜창은 거 같아요. 여기 아니면 어디에서 이 런 옷을 입어보겠어요.” (2016 - Team 2, 엄마) "이런 한복 원단은 처음 봤어요. 집에서 입었던 한 복하고는 다른 거 같아요. 굉장히 화려하고 색이 선명해서 튀더라구요." (2016 - Team 4, 엄마) “얼마 전에 방영한 $K B S$ 드라마 있잖아요. '구르미 그린 달빛' 거기 나온 의상을 대여했어요. 왕이 랑, 내시 그리고 무사복까지요. 학교 축제에서 입 을 건데요, 재밌을 거 같아서 기대되요. 정말 특 이한 옷이잖아요." (2016 - Team 8, 남학생 1)

\section{(2) Conformity}

대부분의 응답자들은 체험용 한복에 대해 긍정적 이었고, 특정 장소에서 남들과 비슷한 모습을 함으로 써 편안함을 느낀다고 표현하였다. 이에 동조성이라 고 명명하였다.

"여기는 다들 이러고 다니니까 저도 입게 되는 거 같아요. 처음에 아이가 입고 싶다고 했을 때는 의 아했는데, 막상 여기 와서 보니까 다들 입고 있더 라구요. 그래서 엄마랑 다 같이 입어보기로 했어 요. 그러니까, 저희 엄마, 저 그리고 딸까지요." (2016 - Team 1, 엄마)

"다들 한복을 입고 있더라구요. 처음엔 이상했는 데 자꾸 보니까 나도 입고 싶어지고, 재밌어 보이 잖아요? 남편도 같이 입으면 좋깄는데, 남편은 싫 다 하고. 그래서 저랑 애들만 입었어요." (2016 Team 3, 엄마)

“제가 작년에 도쿄를 갔었는데요, 사람들이 유카 타를 입고 다니는 모습이 그렁게 인상적이더라구 요. 그런데, 여기 전주에 오니까 사람들이 한복을 입고 있는 거예요. 샵 매니저가 머리까지 손질해 주고, 워낙 많은 사람들이 입으니까, 한복 입는 게 편하게 느껴져요. 한복입고 한옥마을 돌아다 니니까 진짜로 여행을 하고 있는 거 같아서 굉장 히 좋아요." (2016 - Team 2, 엄마)

\section{(3) Sharing memories}

체험용 한복을 대여하는 소비자들은 대부분 여러 명이 함께 대여를 하는 경향을 보였다. 이는 특정한 
장소에서 같은 시간과 경험을 공유하고자 하는 목적 으로 생각되어 추억 공유라고 명명하였다.

"저희는 우리 아이들이 한국의 전통적인 것들을 알 았으면 좋겠어요. 좋잖아요. 한옥도 그렇고 한복도 그렁고. 그래서 일부러 대여했어요. 애들한테 특별 한 기억을 만들어주고 싶었어요. 솔직히 집에서 싸 가지고 오기는 너무 부담스럽고, 이렇게 예쁘지도 않구요. 인터넷에서 알아보니까 주변에 대여하는 곳도 많고 해서 그냥 왔구요. 숙박업소에서 아예 대여까지 해주던데요!” (2016 - Team 3, 아빠) "우리 애들 예쁜 모습을 남겨주고 싶어요. 진짜 예 뻔 나이잖아요. 20대. 이제 곧 자기들 삶을 찾아 독 립할 거구요. 그래서 가족이 함께 여행을 많이 하 려고 노력 중이예요 똑같은 한복을 빌려 입은 이유 도 그래서예요. 애네들 이렇게 예뻔 모습 간직하 고 싶어서. 여기(전주한옥마을). 정말 특별한 거 같아요. 한복입고 보낸 이번 여행이 정말 특별한 기억으로 남을 거 같아요." (2016 - Team 4, 엄마) “친구들끼리 ‘우전사진’ 찍으러 왔어요. 여기가 사 진도 잘 나오고, 한복 입고 찍으면 좋을 것 같아 서 같은 옷으로 일부러 맞춰 입었어요. 여기 친구 (3)는 다른 디자인도 입어보고 싶어 했는데, 이건 '우정사진'이니깐, 안된다고. 똑같아야 한다고! 저희 둘이 막 우겼어요. 그래서 색만 다르게 이렁 게 입었어요. 사진도 많이 찍었구요." (2016 -

Team 7, 친구 1)

“그냥 재밌잖아요! 요즘 애들이 이러면서 많이 놀 아요. 친구끼리요. 한복도 이뻐구요.” (2016 -

Team 7, 친구 3)

“예뻔 '커플 사진’을 찍고 싶었어요. 드레스나 수 트, 이런 건 왠지 너무 특별한 거 같고, 우리 스타 일은 아니예요. 여기 오니까 분위기도 좋고, 한복 이 웬지 좀 더 새롭고 조금은특별한 거 같고 그래 서 좋아요. 한복입어니까 사진이 예쁘게 나오는 거 같아요." (2016 - Team 6, 커플 중 남성)

\section{Conclusion}

본 연구는 대여 한복이 지난 10 년 동안 어떻게 변 화했는지 알아보는 것을 목적으로 하였다. 이를 위해
대여 한복 관련 뉴스 기사를 분석하여 시장 측면의 변화를 알아보고, 실제 대여한 경험이 있는 소비자를 대상으로 심층 면접하여 소비자의 변화를 살펴, 대여 한복 연구의 기초자료를 제공하고자 하였다. 또한 의 례용 한복과 체험용 한복이 서로 다른 소비자를 대상 으로 하는 독립적 상품임을 밝혀, 관련 업체들이 상 품을 개발하고 소비자를 이해하는데 도움을 주고자 하였다. 연구의 결과를 요약하면 다음과 같다.

첫째, 대여 한복 관련 뉴스 기사를 검색하여 분석 한 결과, 양적으로 크게 증가한 것을 알 수 있었고, 이를 통해 대여 한복 시장이 확대되었고, 다양한 대여 한복이 존재한다는 것을 알 수 있었다. 특히 2006년 에는 존재하지 않았던 관광지에서 대여되는 체험용 한복에 대한 내용이 2016년 뉴스의 약 $63 \%$ 정도를 차지하는 분석 결과를 통해 대여 한복의 용도에 변화가 있었음을 알 수 있었다. 기존 대여 한복이 의례용이 었다면 최근에는 의례용뿐 아니라, 문화 체험용으로 도 대여 한복이 이용되고 있다는 점을 알 수 있었다.

둘째, 한복을 대여하는 소비자의 변화를 알아보기 위해, 2006년의 한복 대여 소비자를 대상으로 한 심 층 면접 결과를 기준으로 2016년에 의례용 한복과 체 험용 한복 대여 소비자를 대상으로 심층 면접을 실시 하였다. 면접 내용을 분석하여 비교한 결과, 의례용 한복의 경우 2006년과 2016년의 면접 내용에 큰 차 이는 없었고, 추구혜택으로 적합성, 경제성, 과시성, 유행성, 특수성이 추출되었다. 이에 비해 체험용 한복 은 한복을 특별하다고 인식하는 특이성, 다른 사람들 이 입고 있어서 같이 입게 되었다는 동조성 그리고 함께한 사람들과 특별한 추억을 만들기 위해 입었다 는 추억 공유 등의 추구혜택이 추출되었다. 이로써 의례용 한복과 체험용 한복은 대여 목적과 추구 혜택 이 다른 독립적 상품이라는 것을 알 수 있었다.

본 연구는 대여 한복에 대한 탐색적 연구로서, 시 장 변화와 소비자의 변화를 확인하기 위해 인터넷 뉴 스를 분석하고, 소수의 대여 한복 소비자를 대상으로 심층 면접을 실시하는 등 연구 대상을 한정하였기 때 문에 결과의 일반화에는 제한점을 가지고 있다. 그러 나 기존에 대여 한복 연구가 업체를 중심으로 이루어 진데 비해, 본 연구는 대여 한복 이용 소비자를 대상 으로 질적 연구를 실시하여 의례용 한복과 체험용 한 복의 차이를 구분하고, 각각의 추구혜택을 추출하였 
다는 점에서 학문적 의의가 있다. 이는 두 가지 유형 의 대여 한복 시장을 서로 다른 시장으로 이해해야 한다는 것을 의미하며, 이에 따라 소비자의 요구에 대 응하는 마케팅 전략을 수립하는데 시사점을 제시할 수 있을 것이다.

또한 본 연구의 결과를 바탕으로 대여 한복 시장의 현황을 파악하고 활성화하기 위해, 다음의 연구들이 필요하다고 생각된다. 첫째, 의례용 한복과 체험용 한 복 시장에 나타나고 있는 한복의 스타일에 대한 분석 이 요구된다. 시장의 반응은 소비자가 원하는 바를 반영한 결과물이기 때문에, 이를 통해 소비자가 원하 는 점을 추측할 수 있을 것이다. 그러나 무분별한 소 비자 의견 반영은 한복의 고유성을 약화시킬 위험이 있다. 특히 체험용 한복 착용 소비자들을 면접하는 과정에서는 ‘곤룡포에 갓’을 쓰는 등 엉뚱한 경우가 관찰되어 이에 대한 보완이 시급하다고 생각되었다. 현재 시장에 존재하는 대여 한복의 스타일을 분석하 고, 전통적인 한복의 고유성을 유지할 수 있는 디자 인을 개발하여 시장에 제안하는 시도가 필요하다고 생각된다. 또한 한복 대여 서비스를 제공하는 사업자 들에게 전통 한복에 대한 기본적 지식을 전달하고, 올바른 착장에 대한 교육도 함께 시행해야 할 것으로 판단된다. 둘째, 관광지의 한복 대여 업체의 운영 현 황을 조사할 필요가 있다고 생각된다. 현재 관광지에 난립한 한복 대여점에 대한 규제가 마땅치 않은 상황 이다. 관광지의 한복 대여는 그 특성상 시간제로 운 영되고 있기 때문에, 하루에 몇 차례 대여되는 한복 도 있을 것으로 추측된다. 다수의 사람들이 입는 한 복에 대해 위생적 측면에 대한 조사와 논의가 있어야 할 것으로 생각된다.

\section{References}

Bae, R. T., Lee, M. S., \& Kim, E. J. (2016). A study on the current status of Hanbok brands and aesthetic characteristics. Fashion Business, 20(1), 127141. doi: $10.12940 / \mathrm{jfb} .2016 .20 .1 .127$

Chung, H.-G., \& Lee, M.-J. (2003). A study on the changes of shape for children's Saenghwal Hanbok Jeogori. The Research Journal of the Costume Culture, 11(1), 75-87.
Geum, K. S. (1988). A study on the Korean aesthetic consciousness through the Choson costume. Unpublished doctoral dissertation, Ewah Womans University, Seoul, Korea.

Geum, K. S. (1990). The beauty of swinging and trembling in Korean costume. Journal of the Korean Society of Costume, 15, 121-130.

Giorgi, A. (2004). Phenomenology and psychological research (K. L. Sin, Y. G. Jang, I. S. Park, M. Y. Kim, \& S. E. Jung, Trans). Seoul: Hyunmoonsa. (Original work published 1985)

Han, S. I. (2016, June 09). 단오날 '한복 입고 폴짝', 10 대 新놀이문화 '한놀족' [On DanO 'Jumping in Hanbok', 10's New play culture 'HanNolJok']. Chicnews, Retrieved November 30, 2016, from http:// chicnews.mk.co.kr

Hanbok Advancement Center. (n.d.). 신한복 개발 프 로젝트 [New Hanbok developing project]. Retrieved November 25, 2016, from www.hanbok center.kr/user/nd88962.do

Hong, J. H. (2009). A study on the development of daily Hanbok design and jacquard textile design using Hansan ramie spun-yarn. Unpublished doctoral dissertation. Wonkwang University, Jeollabuk-do, Korea.

Hwang, K. S. (2015). A study on the interaction related to reusability of internet news. Unpublished master's thesis, Kookmin University, Seoul, Korea.

Hwang, B. H. (2015). An Effect on a consumption behaviors according to a value recognition toward traditional culture: Focused on Hanbok, Hanok, and Korean Food, Unpublished doctoral dissertation, Chungnam national university, Daejeon, Korea.

Kang, S., \& Kim, H. L. (2016, June 02). 한복 열풍, 고궁 안에만 불더군요 [Hanbok trend, it's just in old palace: Play with Hanbok, light and darkness]. Seoul news, Retrieved December 03, 2016, from http://www.seoul.co.kr/news/newsView.php? id $=20160602018001$

Kim, J. H. (2012). A study of traditional hanbok exploration of the consumer information and pur- 
chase consciousness through internet community. Unpublished master's thesis, Sungshin Women's University, Seoul, Korea.

Kim, M. H. (2016, March 08). 신세대 한복나들이 유 행, 한복대여점 '봄바람'.. 맞춤시장은 여전히 '찬 바람' [Hanbok Fashion of new generation, Hanbok rental shop, spring wind.. tailoring shop, cold wind]. Financial news, Retrived December 12, 2016, from http://www.fnnews.com/news/20160 3081552589362

Kim, S. H. (2005). A study on Korean style high school uniform. Unpublished master thesis, Ewha Womans University, Seoul, Korea.

Kim, S. J. (2017). A study on design development according to consumer preference research of women's lifestyle Hanbok. Unpublished master's thesis, Hanyang University, Seoul, Kora.

Kim, S.-K., Cho, H.-S., \& Chung, I.-H. (1999). A study on consumption experience and the consciousness for Saenghwal Hanbok( I ): On focus of purchasing, wearing, and unsatisfaction-perceiving. Journal of Korean Traditional Costume, 2(1), 121-134.

Kim, Y.-K. (2010). A study on formative characteristics and aesthetic values of Hanbok shown in print media since 2000. Unpublished doctoral dissertation, Ewah Womans University, Seoul, Korea.

Kim, Y. M. (2016). A study on Hanbok rental shop: Focused on 'Golden Needle', the first Hanbok rental shop. Unpublished master's thesis, Konkuk University, Seoul, Korea.

Korea Communications Agency. (2014). 인터넷 뉴스 이용자 조사 [Research of internet news users]. Retrieved from Korea Communications Agency website: http://www.kca.kr/open content/bbs.do?act= file $\& b c d=$ research $\&$ msg $n o=171 \&$ file $n o=1$

Korea Press Foundation. (2013). (2013) 언론수용자 의 식조사 [2013 Research of the media audience's opinion]. Seoul: Korea Press Foundation.

Korea Rental Association. (n.d.). President Message. Retrieved November 29, 2016, from http://www. korent.or.kr/ company1.php

Lee, N.-Y. (2009). A study on the development of daily Hanbok design for the old man. Unpublished master thesis, Chonnam National University, Gwangju, Korea.

Lim, K.-H., \& Kang, S.-C. (2001). The study of the present circumstance and the prospect of the renting Korean traditional clothing: The Han-Bok. Journal of Korean Traditional Costume, 4(3), 81-88.

Merriam, S. B., \& Tisdell, E. J. (2015). Qualitative research: A guide to design and implementation (4th ed). San Francisco: John Wiley \& Sons.

Park, H.-S. (2004). The life style and purchase behavior of consumers of prestige hanbok. Unpublished master's thesis, Konkuk University, Seoul, Korea.

Park, M. Y. (2005). A study on the franchise of Hanbok rental shop. Unpubished master's thesis, Kyunghee University, Seoul, Korea.

Shim, J.-Y. (2007). A semiotic analysis on the clothing consumption through rental. Unpublished doctoral dissertation, Chonbuk National University, Jeollabuk-do, Korea.

Son, H. N. (2006). The hand of spring/fall fabrics for 'Saenghwal Hanbok'. Unpublished master thesis, Seoul National University, Seoul, Korea.

Yoon, M.-H. (2009). A study on preschool students' uniform design applied with the korean costume for children. Unpublished master thesis, Korea National Open University, Seoul, Korea.

Yoon, Y.-N. (2012). A study on the communication of the next generation with Korean traditional costume, Hanbok. Journal of Korean Traditional Costume, 15(1), 85-95. 